\title{
Functional Expression of the Heteromeric "Olfactory" Cyclic Nucleotide-Gated Channel in the Hippocampus: A Potential Effector of Synaptic Plasticity in Brain Neurons
}

\author{
Jonathan Bradley, ${ }^{1 a}$ Yinong Zhang,, ${ }^{1 a}$ Robert Bakin, ${ }^{2}$ Henry A. Lester, ${ }^{1}$ Gabriele V. Ronnett, ${ }^{2,3}$ and Kai Zinn ${ }^{1}$ \\ ${ }^{1}$ Division of Biology, California Institute of Technology, Pasadena, California 91125, and Departments of ${ }^{2}$ Neuroscience \\ and ${ }^{3 N}$ eurology, Johns Hopkins University, Baltimore, Maryland 21205
}

Cyclic nucleotide-gated (cng) channels are important components of signaling systems mediating sensory transduction. In vertebrate photoreceptors, light activates a signaling cascade that causes a decrease in intracellular cGMP concentrations, closing retinal cng channels. Signal transduction in olfactory receptor neurons is believed to proceed via G-proteinmediated elevation of intracellular cAMP in response to odorant binding by 7 -helix receptors. CAMP opens the olfactory cng channel, which is highly permeable to $\mathrm{Ca}^{2+}$. Here we demonstrate by in situ hybridization and immunohistochemistry with subunit-specific antibodies that both subunits of the heteromeric rat olfactory cng channel are also widely expressed in the brain. Expression of the retinal rod cng channel, however, can be detected only in the eye. In the adult hippocampus, the olfactory cng channel is expressed on cell bodies and processes of CA1 and CA3 neurons. In cultured embryonic hip- pocampal neurons, the channel is localized to a subset of growth cones and processes. We recorded conductances with the electrophysiological characteristics of the heteromeric olfactory cng channel in excised inside-out patches from these cultured neurons. We also show that $\mathrm{Ca}^{2+}$ influx into hippocampal neurons in response to cyclic nucleotide elevation can be detected using fura- 2 imaging. Cyclic nucleotide elevation has been implicated in several mechanisms of synaptic plasticity in the hippocampus, and these mechanisms also require elevation of intracellular $\mathrm{Ca}^{2+}$. Our results suggest that the "olfactory" cng channel could regulate synaptic efficacy in brain neurons by modulating $\mathrm{Ca}^{2+}$ levels in response to changes in cyclic nucleotide concentrations.

Key words: cyclic nucleotide-gated channels; cAMP; cGMP; olfaction; sensory transduction; hippocampus; synaptic plasticity
Cyclic nucleotide-gated (cng) channels open in response to binding of the intracellular cyclic nucleotides cGMP and cAMP. They resemble voltage-gated channels, having six transmembrane domains and a pore region, but they also contain a cytoplasmic region with homology to the cyclic nucleotide binding domains of cGMP- and cAMP-dependent protein kinases (PKG and PKA). The native retinal rod and olfactory cng channels are believed to be heterotetramers composed of two different subunits. The $\alpha$ subunits [also known in the rat as $\mathrm{RCNC} 1$ (retinal) and rOCNC1 (olfactory)] can form homomeric channels (for review, see Zagotta and Siegelbaum, 1996). The $\beta$ subunits (rRCNC2 and rOCNC2) cannot form functional channels on their own, but they oligomerize with the $\alpha$ subunits to create channels with modified properties (Chen et al., 1993; Bradley et al., 1994; Liman and

Received Nov. 11, 1996; revised Dec. 23, 1996; accepted Dec. 30, 1996.

This work was supported by a grant from the National Institutes of Mental Health to K.Z., and by grants from the National Institute of Deafness and Communication Disorders and the W. M. Keck Foundation to G.R. J.B. was supported by a National Institutes of Health (NIH) graduate training grant and Awards for Research College

Scientists Foundation. Y.Z. was supported by a National Research Service Award postdoctoral fellowship from NIH. We thank Norman Davidson, Mary Kennedy, Jun Li, Ming-Ji Fann, Chris Schoenherr, Yasuhito Uezono, David Anderson, Cori Bargmann, and members of the Zinn, Ronnett, Lester, Davidson, Anderson, and Kennedy groups for helpful discussions; Susan Ou and the Caltech Monoclonal Antibody Facility for generation of hybridomas; and Sheri McKinney for hippocampal cultures.

Correspondence should be addressed to Kai Zinn, Division of Biology, California Institute of Technology, Pasadena, CA 91125.

Dr. Bradley's present address: Laboratoire de Neurobiologie, Ecole Normale Superieure, 46 rue d'Ulm, 75005 Paris, France.

a The first two authors contributed equally to this work.

Copyright (C) 1997 Society for Neuroscience 0270-6474/97/171993-13\$05.00/0
Buck, 1994; Korschen et al., 1995). Unlike most voltage-gated and ligand-gated channels, cng channels do not exhibit desensitization but remain open continuously in the presence of cyclic nucleotide.

The incorporation of the rOCNC2 subunit into the olfactory cng channel dramatically affects cyclic nucleotide sensitivity. The heteromeric $\mathrm{rOCNC} 1 / \mathrm{rOCNC} 2$ channel has a much lower $K_{1 / 2}$ for cAMP than the homomeric rOCNC1 channel ( $\sim \mu \mathrm{M}$ vs $47 \mu \mathrm{M})$ (Bradley et al.,1994; Liman and Buck, 1994). Interestingly, both homomeric and heteromeric olfactory channels are more sensitive to cGMP than is the rod channel (Nakamura and Gold, 1987; Frings et al., 1992). Although cGMP has been implicated in olfactory signal transduction, its precise role is unclear (Ingi and Ronnett, 1995; Leinders-Zufall et al., 1995b).

The olfactory cng channel is highly permeable to $\mathrm{Ca}^{2+}$ and is blocked by extracellular $\mathrm{Mg}^{2+}$ in a voltage-dependent manner (Frings et al., 1995). Recent studies suggest that the primary function of the cng channel in olfactory transduction is to facilitate $\mathrm{Ca}^{2+}$ entry into olfactory cilia in response to cAMP elevation. This $\mathrm{Ca}^{2+}$ then opens a $\mathrm{Ca}^{2+}$-activated $\mathrm{Cl}^{-}$channel, which carries $70-80 \%$ of the depolarizing current (Lowe and Gold, 1993) .

The definitive identification of functional $\mathrm{Ca}^{2+}$-permeable cng channels in brain neurons would be of considerable importance, because such channels could modulate intracellular $\mathrm{Ca}^{2+}$ levels in response to fluctuations in intracellular cyclic nucleotide concentrations. All known forms of synaptic plasticity involve elevation of intracellular $\mathrm{Ca}^{2+}$. cAMP elevation is required for long-term potentiation (LTP) in the mossy fiber pathway of the hippocampus and has also been implicated in a long-lasting form of LTP, L-LTP, in hippocampal CA1 neurons (Frey et al., 1993; Huang et 
al., 1994; Weisskopf et al., 1994; Huang and Kandel, 1996). Nitric oxide (NO) is also believed to be involved in LTP in CA1 neurons (for review, see Schuman and Madison, 1994), and one of the major effectors of NO is soluble guanylyl cyclase (GC). Finally, in the cerebellum, cAMP has been implicated in LTP at parallel fiber synapses (Salin et al., 1996), whereas NO and cGMP may be involved in the induction of long-term depression (LTD) (for review, see Linden, 1994).

\section{MATERIALS AND METHODS}

Reverse transcription (RT)-PCR assays. RNA was prepared from freshly dissected tissue by extraction with Trizol (Life Technologies, Gaithersburg, MD) according to the manufacturer's protocol. First-strand cDNA was primed with oligo-dT from $25 \mu \mathrm{g}$ of total RNA pretreated with DNaseI. cDNA was synthesized using the SuperScript II enzyme (Life Technologies) in $50 \mu \mathrm{l}$ reactions at $42^{\circ} \mathrm{C}$ for $2 \mathrm{hr}$. The cDNA was quantitated for normalization using PCR (15 and 20 cycles; amplification does not begin to plateau within this range of cycle numbers) with $\beta$-actin primers. The annealing temperature for all primers was $56^{\circ} \mathrm{C}$. The rOCNC2 intron primer sequence is 5'-CAG AAG GCA AGC ACT GAA TGA (GenBank U76219), and this was used together with a cDNA primer (5'-GGC CAC CAG GTA ACT GTG CTG) to test for the presence of genomic DNA.

In situ hybridization to tissue sections. In situ hybridization was carried out by a modification of the protocol of Schaeren-Wiemers and GerfinMoser (1993). All of the probes for the cng channels were derived primarily from the $3^{\prime}$ untranslated regions of the mRNAs, but they also contain some sequences encoding the divergent $\mathrm{C}$ termini of the channels. All three probes were transcribed from PCR-amplified templates generated from plasmid subclones (Bradley et al., 1994). The rOCNC1 probe is 815 nucleotides (nt) long and contains sequences encoding 41 C-terminal residues. The rOCNC2 probe is 693 nt long and contains sequences encoding $58 \mathrm{C}$-terminal residues. The $\mathrm{rRCNC} 1$ probe is $700 \mathrm{nt}$ long and contains sequences encoding $91 \mathrm{C}$-terminal residues [from a subclone of a $3^{\prime}$ fragment of the rat rod channel mRNA generated from primary retinal cDNA using RACE amplification (Frohman, 1994); sequence has been deposited in GenBank (U76220)]. Probes were partially hydrolyzed to 200-350 nt before use. There is no significant homology between the three probes, and we showed directly by in situ hybridization to transiently transfected HEK293 cells expressing high levels of each of the channel mRNAs that the probes could not cross-hybridize under our in situ conditions. They also fail to cross-hybridize in Northern blot assays, in which synthetic RNA transferred to a filter is hybridized with radiolabeled or digoxigenin-labeled RNA probes (data not shown).

Sections were collected onto presubbed slides (Superfrost plus slides; Fisher Scientific, Houston, TX) and allowed to dry at room temperature for no more than $3 \mathrm{hr}$. Before acetylation, the sections were digested with proteinase $\mathrm{K}(50 \mu \mathrm{g} / \mathrm{ml})$ for $5 \mathrm{~min}$ followed by fixation in $4 \%$ paraformaldehyde. Prehybridization was as described (Schaeren-Wiemers and Gerfin-Moser, 1993), except for the addition of $0.1 \%$ Triton X-100. This and each subsequent step were performed in batches of five slides per probe in slide mailers (Baxter, Deerfield, IL), each slide with a different tissue. Hybridization was at a probe concentration of $600 \mathrm{ng} / \mathrm{ml}$ in prehybridization solution without Triton $\mathrm{X}-100$ at $70^{\circ} \mathrm{C}$ for $12-15 \mathrm{hr}$. After hybridization, the sections were equilibrated in $2 \times$ SSC, incubated with RNase A ( $1 \mathrm{ng} / \mathrm{ml})$ for $20 \mathrm{~min}$ at $37^{\circ} \mathrm{C}$, and then washed extensively in $2 \times \mathrm{SSC}$ at room temperature before a high stringency wash in $0.2 \times$ SSC at $70^{\circ} \mathrm{C}$ for $60 \mathrm{~min}$. Probes were detected with an antidigoxigenin antibody conjugated to alkaline phosphatase (AP). All antibodycontaining solutions included $0.1 \%$ Tween-20. A positive signal is indicated by the purple AP enzymatic reaction product using the substrate nitro-blue tetrazolium.

Generation of antibodies against rOCNC1 and rOCNC2. A rat rOCNC1-specific polyclonal antibody was generated against a fusion protein containing amino acids 559-664 of rOCNC1, made in the pTrcHisA expression vector. Fusion protein was purified using a nickel column and injected into rabbits for antibody synthesis. Antibody was affinity-purified using a fusion protein column, as described previously (Roskams et al., 1994).

To make monoclonal antibodies (mAbs) against rOCNC2, we immunized mice with a glutathione- $S$-transferase (GST) fusion protein extending from residue 392 to the $C$ terminus of the channel (residue 575). Hybridoma supernatants were screened by dot blot against the GST fusion protein (positively) and against GST protein (negatively). In the dot blot screen, no hybridomas were found to react against a rOCNC1 GST fusion protein spanning residues 500-664. Eighteen clones were saved, and two (7B11 and 7H2) were subcloned. All rOCNC2 data in this paper were generated with antibody 7B11.

Immunoblot analysis. Soluble whole-tissue homogenates of experimental samples were prepared in $25 \mathrm{~mm}$ Tris- $\mathrm{HCl}$ buffer, $\mathrm{pH} 7.4$, containing $1 \mathrm{~mm}$ EDTA and $0.1 \%$ Triton X-100, and normalized for protein content using the BCA protein assay kit (Pierce). For immunoblotting, affinitypurified anti-rOCNC1 was used at a 1:500 dilution, and culture supernatant containing anti-rOCNC2 mAb was used at a 1:100 dilution. Bands were visualized using an AP-linked secondary antibody (Boehringer Mannheim, Indianapolis, IN).

Immunohistochemistry. Adult Sprague Dawley rats were anesthetized with xylaket and xylazine and then perfused with saline followed by $4 \%$ freshly depolymerized paraformaldehyde in PBS (4\% PFA solution). Brains were removed carefully and post-fixed in $4 \%$ PFA for $2 \mathrm{hr}$ at $4^{\circ} \mathrm{C}$. Tissue was cryoprotected in $20 \%$ glycerol in PBS overnight at $4^{\circ} \mathrm{C}$. The next day, brain tissue was washed in $50 \mathrm{~mm}$ Tris, $\mathrm{pH} 7.4$, containing $1.5 \%$ $\mathrm{NaCl}$ (TBS buffer) and frozen onto the cryostat stage with dry ice. Tissue was sectioned using a Zeiss sliding microtome to a thickness of $20 \mu \mathrm{m}$. Floating sections were rinsed overnight in PBS to remove glycerol and then permeabilized in TBS containing $0.2 \%$ Triton X-100 and $4 \%$ normal serum for $30 \mathrm{~min}$. Primary antibody was added at the appropriate dilution (1:1000) in TBS containing $0.1 \%$ Triton $\mathrm{X}-100,2 \%$ normal serum, and $0.02 \%$ sodium azide overnight at $4{ }^{\circ} \mathrm{C}$ with gentle agitation. The next day, sections were rinsed in TBS containing $1 \%$ normal serum and incubated with biotinylated secondary antibody at 1:200 dilution in TBS containing $1.5 \%$ normal serum for $1 \mathrm{hr}$ at room temperature. Staining was visualized using the Vectastain Elite Kits (Vector Labs, Burlingame, CA) and developed using diaminobenzidine (Sigma, St. Louis, MO) and hydrogen peroxide in $50 \mathrm{~mm}$ Tris, $\mathrm{pH}$ 7.4. Sections were mounted by floating sections onto Superfrost plus slides (Fisher), air-dried for $2 \mathrm{~min}$, and sequentially dehydrated, followed by xylene washes. Slides were mounted with DPX (Fluka, Buchs, Switzerland) cytological mountant and coverslipped.

Hippocampal culture. Hippocampi were dissected from embryonic day 17 (E17) brains and chopped into $\sim 1 \mathrm{~mm}$ pieces. After digestion for 15 min at $37^{\circ} \mathrm{C}$ with $0.25 \%$ trypsin and $2 \mu \mathrm{g} / \mathrm{ml}$ DNase I, the cells were dispersed with gentle trituration and plated on poly-D-lysine/laminincoated coverslips. Cells were cultured in Neurobasal medium at $37^{\circ} \mathrm{C}$ under $5 \% \mathrm{CO}_{2}$ for between 1 and $14 \mathrm{~d}$. For immunofluorescence, cells were fixed with methanol at $-20^{\circ} \mathrm{C}$ and then incubated with antirOCNC2 mAb supernatant, followed by fluorescein isothiocyanate (FITC)-labeled secondary antibody (1:200; Jackson ImmunoResearch Labs, West Grove, PA).

Electrophysiology. Whole-cell and inside-out patch recordings were conducted in a chamber that was perfused constantly with bath solution containing $140 \mathrm{~mm} \mathrm{NaCl}, 5 \mathrm{~mm} \mathrm{KCl}, 5 \mathrm{~mm}$ EGTA, and $10 \mathrm{~mm}$ HEPES, $\mathrm{pH}$ 7.2. An Axopatch 1D patch-clamp amplifier (Axon Instruments, Foster City, CA) was used in all recordings. For whole-cell patch recordings, pipettes were filled with $140 \mathrm{~mm} \mathrm{CsCl}, 5 \mathrm{~mm} \mathrm{EGTA}, 0.5 \mathrm{mM} \mathrm{CaCl}_{2}$, and $10 \mathrm{~mm}$ HEPES, pH 7.2. For the inside-out patch recordings, the pipette solution was the same as the bath solution. An 18-line RSC-100 solution changer (Biologic) was used in drug delivery. The data were low-pass-filtered at $3 \mathrm{kHz}$ and digitized at $5 \mathrm{kHz}$ (for whole-cell recording) and $20 \mathrm{kHz}$ (for inside-out patch recording) using a Digidata 1200 interface. pCLAMP (Axon Instruments) was used in subsequent data analysis.

Measurement of intracellular $\mathrm{Ca}^{2+}$. Measurements of changes in intracellular $\mathrm{Ca}^{2+}$ concentrations were made by loading cultured hippocampal neurons with fura-2 AM (Molecular Probes, Eugene, OR) and measuring fluorescence emissions at 340 and $363 \mathrm{~nm}$. A Zeiss Axioskop microscope and a Zeiss Plan-Neofluar $25 \times$ objective were used. Samples were illuminated by a $75 \mathrm{~W}$ xenon bulb, and a computer-controlled filter changer (Lambda-10; Sutter Instruments, Novato, CA) was used to switch the excitation filters. An intensified CCD camera (Hamamatsu, Bridgewater, $\mathrm{NJ}$ ) was used to detect fluorescence. Images were acquired and analyzed with VideoProbe system (ETM Systems, Irvine, CA) hardware and software.

Hippocampal neurons were loaded with fura-2 $\mathrm{AM}$ in a $\mathrm{Mg}^{2+}$-free buffer containing (in $\mathrm{mM}$ ): $140 \mathrm{NaCl}, 3 \mathrm{KCl}, 2 \mathrm{CaCl}_{2}, 10$ glucose, and 10 HEPES, pH 7.4. Fura-2 AM was dissolved in dry dimethyl sulfoxide (DMSO) and diluted in the buffer. The final loading solution contained 5 $\mu \mathrm{M}$ fura-2 AM, $0.1 \%$ pluronic acid, and $0.5 \%$ DMSO. Neurons were 

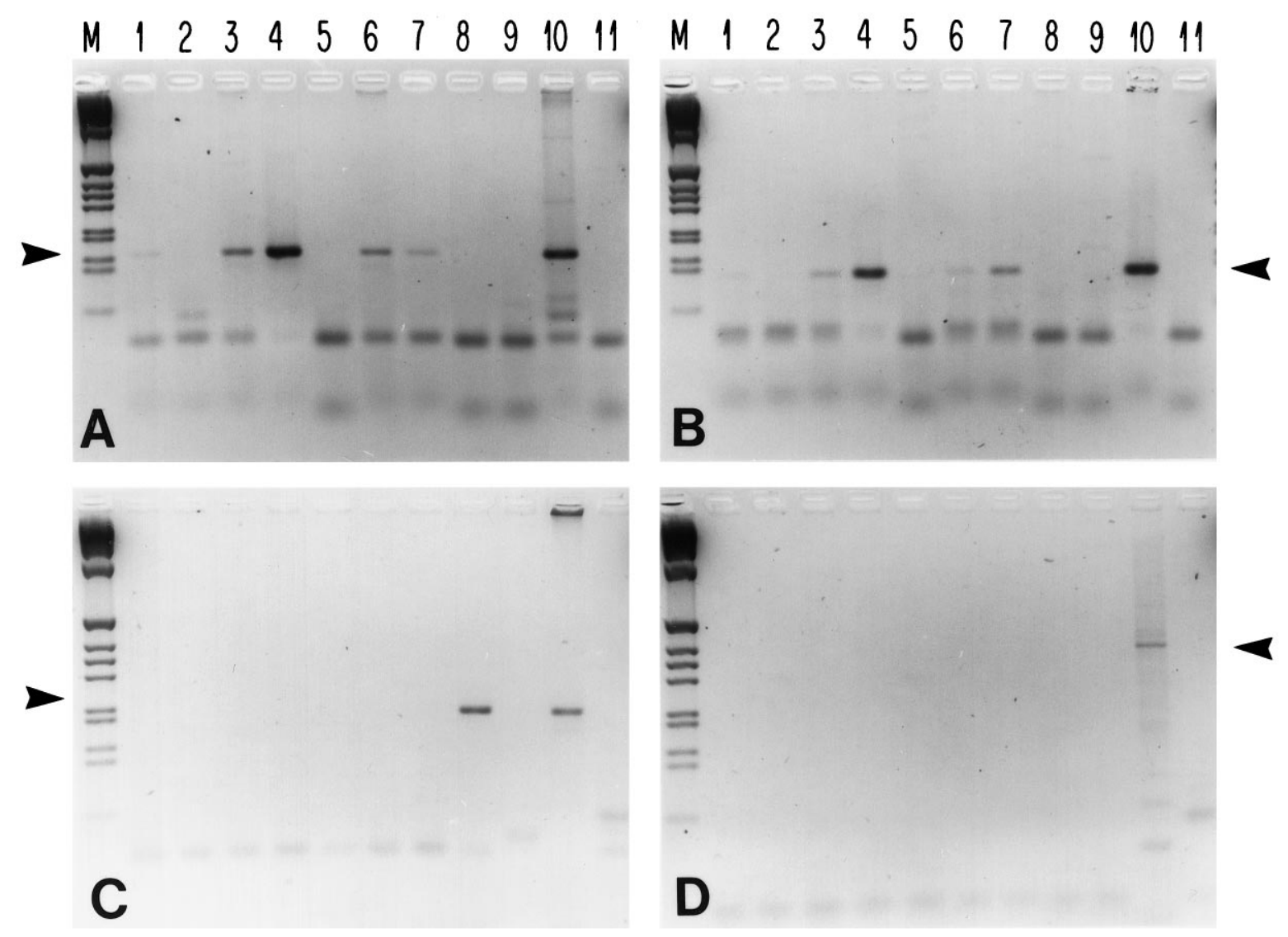

Figure 1. Olfactory cng channel mRNAs are expressed in the brain. Semiquantitative RT-PCR assays were used to examine expression of mRNAs encoding $\mathrm{rOCNC} 1(A), \mathrm{rOCNC} 2(B)$, and $\mathrm{rRCNC} 1(C)$. Primers specific for the $3^{\prime}$ untranslated regions of the three mRNAs were used to amplify oligo-dT-primed cDNA made from RNA from various adult rat tissues (35 cycles of amplification). In $D$, primers spanning an intron/exon boundary from the rOCNC2 gene were used for amplification, to control for the possible presence of genomic DNA in the mRNA preparations. The cDNA concentrations were normalized by amplification (15 and 20 cycles) with $\beta$-actin primers, and $\sim 1 \mathrm{ng}$ of cDNA was used per amplification. Lanes: $M$, DNA markers; 1-9, cDNAs from 1, cortex; 2, liver; 3, olfactory bulb; 4, nasal epithelium; 5, brainstem; 6 , cerebellum; 7, hippocampus; 8, eye; 9 , heart; 10 , genomic rat DNA; 11 , no DNA. The positions of the appropriate amplified bands are indicated by arrows. The rOCNC1 PCR product is 159 bp $(A)$; the rOCNC2 product is $122 \mathrm{bp}(B)$; the rRCNC1 product is $202 \mathrm{bp}(C)$; and the genomic intron product is $\sim 363$ bp $(D)$. The figure is a negative image of an ethidium bromide-stained agarose gel.

incubated in the loading solution for $45 \mathrm{~min}$ at $37^{\circ} \mathrm{C}$ and then washed twice in the $\mathrm{Mg}^{2+}$-free buffer. Image pairs were collected at $20 \mathrm{sec}$ intervals, and each image was an average of eight frames. Fluorescence ratios were calculated with the VideoProbe software.

\section{RESULTS}

\section{Analysis of cng channel mRNA expression patterns by RT-PCR}

The expression patterns of three cng channel subunit mRNAs were surveyed using semiquantitative RT-PCR assays. We made first-strand cDNA from RNA purified from various neuronal and non-neuronal adult rat tissues. The relative concentrations of the cDNAs in the RT-PCR assays were adjusted using $\beta$-actin mRNA content as an internal standard (for details, see Materials and Methods). The cDNAs were then amplified with primers specific for $\mathrm{rOCNC} 1, \mathrm{rOCNC} 2$, and $\mathrm{rRCNC} 1$ sequences, as well as with a primer set spanning an intron/exon boundary from the rOCNC2 gene, to control for possible genomic DNA contamination. None of our cDNA samples amplified with the intron primer, showing that the observed signals were not caused by genomic DNA contamination (Fig. 1D).

We find that rOCNC1 and rOCNC2 mRNA levels, as expected, are highest in olfactory epithelium. Diagnostic rOCNC1 and
rOCNC2 amplification products were also generated, however, from cDNAs derived from the hippocampus, olfactory bulb, cortex, and cerebellum. These mRNAs were not detected in the eye, heart, or liver (Fig. 1 $A, B$ ). In contrast to the widespread expression of rOCNC1 and rOCNC2 mRNAs, rRCNC1 mRNA was detected only in the eye (Fig. 1C). Analysis of these gels using Southern blot hybridization did not reveal amplification products in lanes that appear negative in Figure 1 (data not shown).

Expression of rOCNC1 mRNA in the brain was reported previously in two studies using similar RT-PCR assays (Elhusseini et al., 1995; Kingston et al., 1996). Kingston et al. (1996) also found amplification products diagnostic of rRCNC1 mRNA when hippocampal cDNAs were analyzed, which contradicts our results. Surprisingly, in their experiments the apparent expression level of rRCNC1 mRNA was higher in the hippocampus than in the retina.

\section{In situ hybridization analysis of cng channel mRNA expression in the rat hippocampus}

The RT-PCR analysis described above indicates that mRNAs encoding both subunits of the olfactory cng channel are expressed in the hippocampus. In addition, hippocampal staining is promi- 
nent in coronal or sagittal adult brain sections stained with antibodies against the olfactory channel subunits (see below). Because the effects of cyclic nucleotides and $\mathrm{Ca}^{2+}$ elevation on synaptic plasticity have been investigated extensively in the hippocampus, we decided to focus our subsequent analysis on this brain region. We examined channel mRNA expression patterns at the cellular level using $20 \mu \mathrm{m}$ cryostat sections from 2 -month-old rats. These were analyzed by in situ hybridization with digoxigenin-labeled antisense riboprobes specific for rOCNC1, rOCNC2, and rRCNC1 mRNAs, as well as with positive and negative control probes. The channel mRNA probes were all derived from $3^{\prime}$ untranslated sequences and the divergent regions encoding the $\mathrm{C}$ termini of the proteins, and they displayed no detectable crosshybridization (for details, see Materials and Methods). Hybridization was detected using AP-conjugated anti-digoxigenin antibody.

rOCNC1 and rOCNC2 mRNAs are expressed in the CA1 and CA3 regions of the hippocampus and in the dentate gyrus (Fig. $2 A, B)$. These probes do not hybridize nonspecifically to cell bodies, as shown by the positive controls (nasal epithelium sections; Fig. 2G,H), in which a clear border between the expressing neuroepithelium and nonexpressing respiratory epithelium is visible. Neither probe hybridizes to eye sections (data not shown).

The complete pattern of hippocampal neuronal cell bodies is visualized by hybridization to a probe for SCG10 mRNA (Fig. 2D; Stein et al., 1988). To assess background levels of hybridization (Fig. 2E), a hippocampal section was hybridized to a probe for the I7 olfactory receptor mRNA (Buck and Axel, 1991), which is not expressed in any region of the brain, as determined by RT-PCR analysis (data not shown). We observe no hybridization to the rRCNC1 probe in the hippocampus (Fig. 2C). The amount of AP reaction product in this panel is the same as the background levels visualized in Figure 2E. Kingston et al. (1996) showed previously that rOCNC1 mRNA is widely expressed in the hippocampus using in situ hybridization. They also observed hybridization of an rRCNC1 probe to hippocampal sections, however, in disagreement with our results. The integrity of the rRCNC1 probe used in our studies was demonstrated by the robust signal this probe produced when hybridized to retinal sections (Fig. 2 I) (note that this signal was produced in a $4 \mathrm{hr}$ AP development reaction, whereas the section in Fig. $2 C$ was developed for $20 \mathrm{hr}$ ). The SCG10 probe also hybridized strongly to the eye, but to the ganglion cell layer rather than to inner segments (data not shown).

\section{Immunocytochemical analysis of olfactory cng channel expression}

To examine expression of the olfactory channel subunits, we generated antibodies against segments of the channels expressed in Escherichia coli. Anti-rOCNC1 is an affinity-purified rabbit polyclonal antiserum against the C-terminal 108 amino acids of rOCNC1. Anti-rOCNC2 is a mouse $\mathrm{mAb}$ against the $\mathrm{C}$-terminal 183 amino acids of rOCNC2 (for details, see Materials and Methods). To examine the specificity of these antibodies, we performed immunoblotting experiments on lysates from nasal epithelium and hippocampus. Each antibody recognized a single band of the appropriate molecular weight in hippocampal lysates (Fig. 3). rOCNC1 is $\sim 78 \mathrm{kDa}$, and rOCNC2 is $\sim 67 \mathrm{kDa}$. Single bands of the same apparent molecular weights are seen when the antibodies are used to probe lysates from nasal epithelium (data not shown). No immunoreactive bands were observed when the antibodies were preabsorbed with the appropriate fusion protein before incubation with the filters (Fig. 3).

To examine the patterns of expression of the channel subunits in the brain, we performed immunohistochemical staining experiments on brain sections from adult rats. Low-power views of coronal sections display widespread staining with both antibodies, and their staining patterns are very similar (Fig. 4A,B). Again, when the antibodies were preabsorbed with the appropriate fusion protein, staining was eliminated (Fig. 4C,D).

Hippocampal cell bodies are prominently stained with both antibodies (Fig. 5A,B). We also stained sagittal brain sections and found that granule and Purkinje neurons in the cerebellum express both channel proteins, as do many olfactory bulb neurons (data not shown). Examination of hippocampal sections under higher magnification reveals that the two channel subunits are likely to be expressed in the same neurons, with overlapping subcellular localizations. rOCNC1 is expressed on both cell bodies and dendrites in the $\mathrm{CA} 3$ region (Fig. $5 C, G$ ), whereas rOCNC2 immunoreactivity is relatively more intense in cell bodies (Fig. $5 D, H)$. A similar pattern of expression of the two subunits is observed in the CA1 region (Fig. 5E,F). Interestingly, highmagnification views of CA3 neurons stained with either antibody show prominent punctate staining over the cell bodies and proximal processes (Fig. 5G,H). We speculate that these may be synapses at which the channel subunits are expressed at high levels.

We also stained hippocampal sections with a mAb against rRCNC1 (Molday et al., 1991) but saw no immunoreactivity (data not shown). In control experiments, this anti-rRCNC1 mAb exhibited strong staining of transfected HEK293 cells expressing rRCNC1 but did not stain cells expressing rOCNC1 and/or rOCNC2 (data not shown). These results support our conclusion from RT-PCR and in situ hybridization assays (Figs. 1, 2) that the retinal rod channel is not expressed in the hippocampus.

\section{rOCNC2 is localized to growth cones and processes of cultured hippocampal neurons}

To examine expression of the olfactory channel in individual hippocampal neurons, we cultured dissociated E17 hippocampi on laminin/poly-lysine for periods of 1-14 d and stained these cultures with anti-rOCNC2 mAb. Two-day-old cultures are shown in Figure 6. rOCNC2 is localized to internal membranes in cells that have not yet extended processes (Fig. 6A,B). After process extension begins, high levels of rOCNC2 protein are observed on growth cones (Fig. 6B). A subset of processes is also labeled by the antibody (Fig. 6C,D).

The cells that labeled with the antibody were glial fibrillary acidic protein-negative, confirming their neuronal phenotype. A similar pattern of labeled cells was observed with anti-rOCNC1 antisera, but these antibodies also exhibited high nonspecific

Figure 2. In situ hybridization analysis of olfactory cng channel mRNA expression in the adult hippocampus. mRNAs were detected by high-stringency in situ hybridization to $20 \mu \mathrm{m}$ sections using digoxigenin-labeled antisense RNA probes derived from nonconserved regions of the channel mRNAs (primarily $3^{\prime}$ untranslated regions), followed by detection with AP-conjugated anti-digoxigenin antibody. A positive signal is indicated by the presence of a purple AP reaction product. $A-F$, Coronal sections of adult hippocampus: $A$, rOCNC1; $B$, rOCNC2; $C$, rRCNC1; $D, \mathrm{SCG} 10$ (positive control); $E$, I7 olfactory receptor (negative control); $F$, high-power view of rOCNC1 mRNA expression; $G$, rOCNC1 probe control (horizontal section of olfactory/ respiratory epithelium border); $H$, rOCNC2 probe control (same as $G$ ); $I, \mathrm{rRCNC1}$ probe control (horizontal section of retina). (Figure legend continues) 

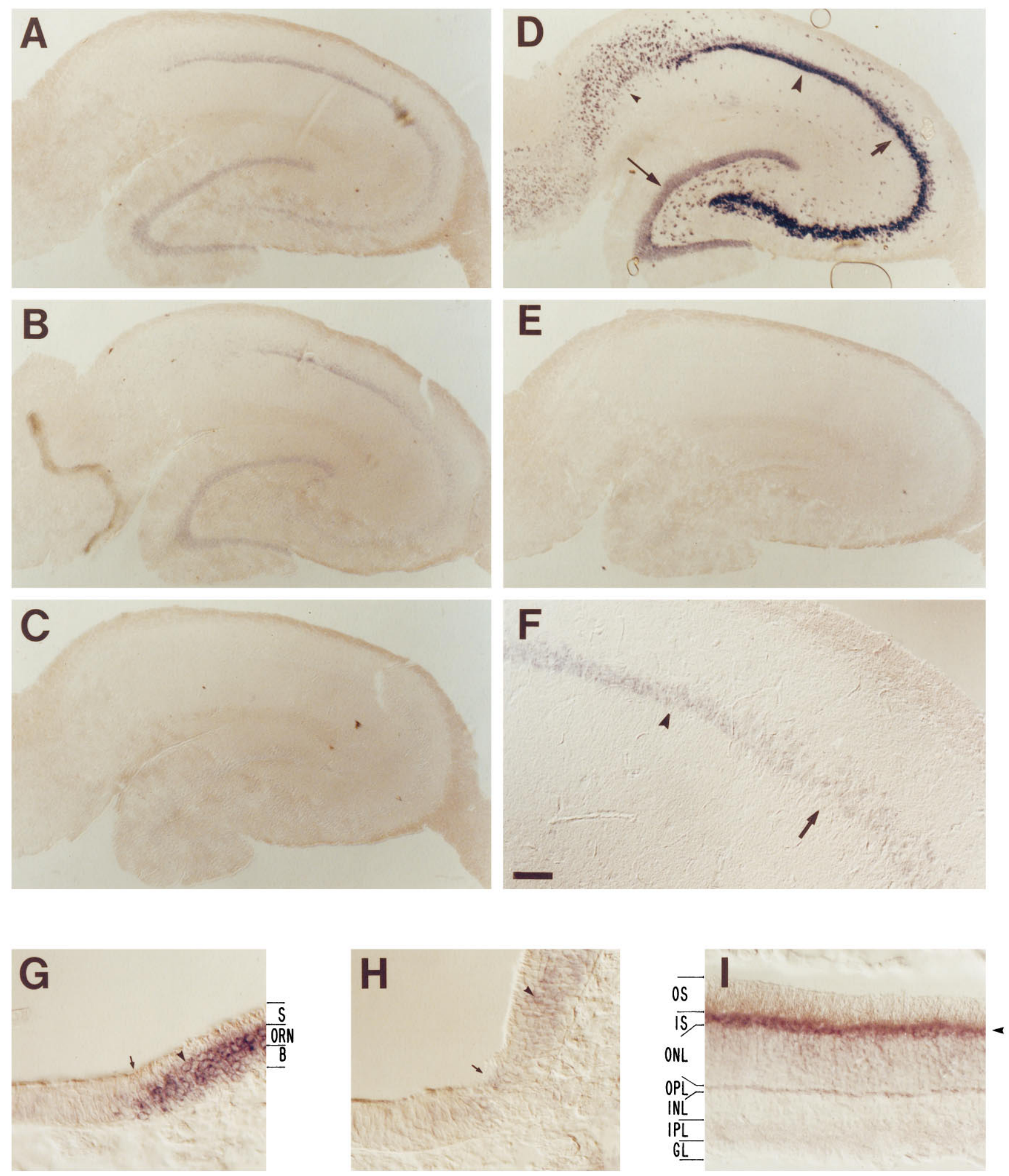

In $A$ and $B$, but not in $C$, purple reaction product is visualized in the dentate gyrus, CA3, and CA1 cell body layers [compare with $D$, in which these regions are labeled dentate gyrus (thin arrow), CA3 (thick arrow), CA1 (large arrowhead)]. The level of nonspecific background hybridization is shown in E; I7 olfactory receptor mRNA is not expressed in the brain. $F$, Higher-magnification view showing the border between the CA3 (thick arrow) and CA1 (arrowhead) regions. In the probe control panels $(G-I)$, note that hybridization of the rOCNC1 and rOCNC2 probes (arrowheads) is restricted to the olfactory receptor neuron $(O R N)$ layer of the olfactory epithelium [the border between respiratory (left) and olfactory (right) epithelium is at the arrow in $G$ and $H$; also see Bradley et al., 1994]. $S$, Sustentacular cell layer; $B$, basal cell layer. In $I$, hybridization of the rRCNC1 probe is largely restricted to the inner segments (IS) of the photoreceptors (arrowhead); the other layers are outer segments $(O S)$, outer nuclear layer $(O N L)$, outer plexiform layer $(O P L)$, inner nuclear layer $(I N L)$, inner plexiform layer $(I P L)$, and ganglion cell layer $(G L)$. rOCNC1 and rOCNC2 probes do not hybridize to retina. The AP development reaction was incubated for $20 \mathrm{hr}$ for the sections in $A-C$ and $E-H$ and for $4 \mathrm{hr}$ for the sections in $D$ and $I$. Scale bars: $A-E, 290 \mu \mathrm{M} ; F, 72 \mu \mathrm{M} ; G-I, 36 \mu \mathrm{M}$. 


\section{Antibody OCNC1 OCNC2 Antigen $\mathrm{kDa}$ 211 -} $117-$ $81-$
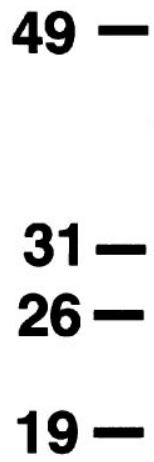

Figure 3. Immunoblot analysis of rOCNC1 and rOCNC2 in the hippocampus. Homogenates were prepared from whole adult hippocampus, and $200 \mu \mathrm{g}$ of protein per gel lane were electrophoretically separated on a 7-15\% SDS-PAGE and transferred onto a nitrocellulose membrane. After blocking, lanes were separated and probed with either anti-rOCNC1 antiserum or anti-rOCNC2 mAb. rOCNC1 is $78 \mathrm{kDa}$, and rOCNC2 is 67 $\mathrm{kDa}$ ( - lanes). In each case, immunoreactivity was blocked when the antibodies were preabsorbed with a 10-fold excess of the appropriate purified fusion protein antigen (+ lanes).

background labeling on these cultures (data not shown). We observed no specific labeling of the dissociated cultures with anti-rRCNC1 mAb (Molday et al., 1991).

In older (14-d-old) cultures, extensive labeling of a subset of neuronal processes with anti-rOCNC2 mAb was observed. A comparison of this labeling pattern to expression of microtubuleassociated protein- 2 in the same cultures suggested that most of these processes are dendrites. A subset of the processes labeled with antibodies against the presynaptic synapsin protein was also labeled with anti-rOCNC2, however, suggesting that axons can express the protein. We also saw prominent colocalized punctate labeling with anti-rOCNC2 and anti-synapsin (data not shown). These results, together with the punctate staining seen in Figure $5 G, H$, suggest that rOCNC2 is localized to synapses in both cultured neurons and the intact brain. We cannot determine from these results, however, whether rOCNC2 (and by inference the $\mathrm{rOCNC} 1 / \mathrm{rOCNC} 2$ heteromeric cng channel) is expressed on preor postsynaptic terminals. Because both axonal and dendritic staining was observed, and both types of processes display punc- tate labeling, it is possible that the channel is expressed on both types of terminals but in different neurons.

\section{Detection of cng channel activity in cultured hippocampal neurons}

It has been shown previously that a conductance activated by membrane-permeable cGMP analogs can be observed in cultured rat hippocampal neurons (Leinders-Zufall et al., 1995a). Similar conductances were seen in retinal bipolar (Nawy and Jahr, 1991) and ganglion cells (Ahmad et al., 1994). In all of these electrophysiological studies, whole-cell recording techniques were used, and high concentrations of the membrane-permeable cGMP analogs were applied to intact cells. One cannot determine, therefore, whether the currents observed were from channels directly gated by cGMP or from channels whose activities are modulated via a cGMP-dependent kinase activity.

To definitively determine whether dissociated rat hippocampal neurons express functional cng channels gated by cAMP and cGMP, we used patch-clamp recording techniques. Both wholecell and excised inside-out patch recordings were conducted on E17 embryonic neurons cultured for $1-3 \mathrm{~d}$. Figure $7 A$ shows examples of cyclic nucleotide-activated whole cell currents using a pipette backfilled with $100 \mu \mathrm{M}$ cAMP from one cell (left) or 100 $\mu \mathrm{M}$ cGMP from another cell (right). The top set of traces shows the currents immediately after rupture of the patch. The bottom set of traces was recorded 4 min after patch rupture, by which time cyclic nucleotides had diffused into the cells. Both cells responded to cyclic nucleotides, and the whole-cell currents showed slight outward rectification (Fig. 7A). Similar conductances did not appear in experiments performed without cyclic nucleotides in the pipette. The difference in amplitude between the currents in the two cells is likely to reflect differences in the number of channels on their surfaces. Whole-cell currents activated by cAMP or cGMP could be recorded from $>90 \%$ of the neurons, and these currents were blocked by $10 \mathrm{~mm}$ extracellular $\mathrm{Mg}^{2+}$ at negative membrane potentials (data not shown).

Cng channel activities were then examined directly using excised, inside-out membrane patches taken from cell bodies. Figure $7 B$ shows an example of openings of hippocampal cng channels in one patch. The cytosolic face of the patch was first perfused with $10 \mu \mathrm{M}$ cAMP followed by $10 \mu \mathrm{M}$ cGMP, at the times indicated by the horizontal bars. Both the patch pipette and the perfusion solution were free of divalent cations. The frequency of obtaining a patch with analyzable cng channel activity was very low. Of 632 successful patches, 17 showed robust, long-lasting cng channel activities on perfusion of agonist. Channels in these patches could all be activated by low micromolar cAMP concentrations, consistent with the properties of the heteromeric olfactory channel (Bradley et al., 1994; Liman and Buck, 1994). Retinal rod and cone cng channels are unresponsive to cAMP at less than millimolar concentrations.

Because the density of open channels in the patches was so low, we have not conducted systematic dose-response experiments for cAMP and cGMP. In the 17 patches analyzed, openings continued for the duration of cyclic nucleotide application (Fig. 7B). A few other patches displayed cng channel activity that decayed within seconds during maintained agonist application (data not shown). In our experiments, cng channel activities were recorded from almost all of the neurons in whole-cell recording configuration but from only a small percentage of neurons in excised patch recording. This discrepancy could be explained by the pattern of cng channel protein localization in embryonic hippocampal cultures 

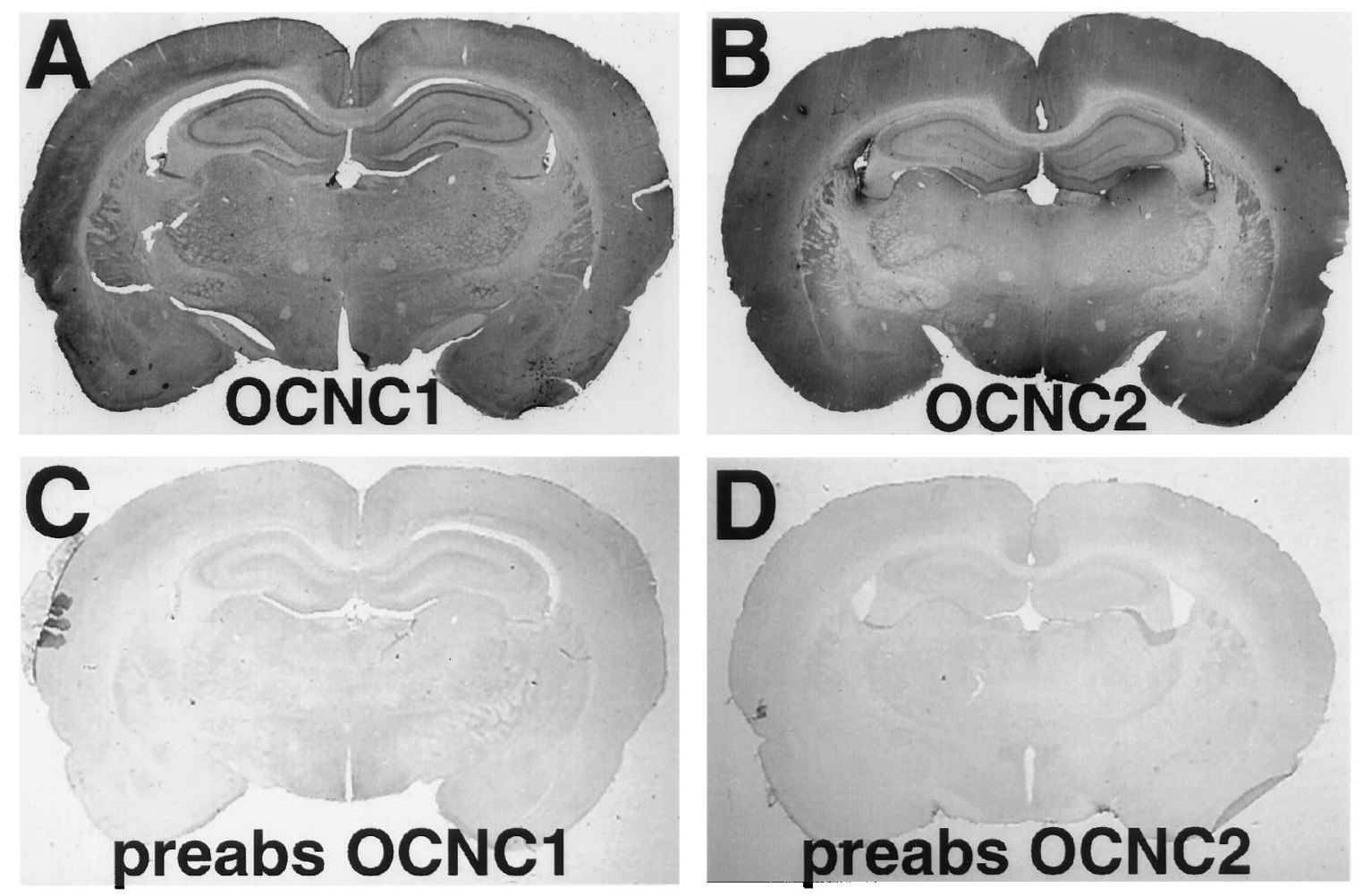

Figure 4. Immunolocalization of rOCNC1 and rOCNC2 in whole brain sections. Coronal sections of adult rat brains were immunostained, using horseradish peroxidase immunohistochemistry, with affinity-purified antibody to rOCNC1 $(A, C)$ or anti-rOCNC2 $\mathrm{mAb}(B, D)$. In $C$ and $D$, the antibodies were preabsorbed with a 10-fold excess of the appropriate fusion protein. Widespread immunoreactivity is seen with both antibodies. Staining is particularly strong in the hippocampal pyramidal cell layers and in the dentate gyrus. A high level of staining is also observed in cortex.

(Fig. 6). Cng channel proteins are expressed prominently in growth cones and processes in 2-d-old cultures but rarely in the cell bodies from which patches were excised.

The single-channel properties of the hippocampal cng channel resemble those of the native olfactory channel in several other ways. Amplitude histograms and current-voltage relationships indicated that the hippocampal cng channel detected in excised patch recording is outwardly rectifying. At $+80 \mathrm{mV}$, the estimated single-channel conductance is $31 \pm 3.2 \mathrm{pS}$, and at $-80 \mathrm{mV}$ it drops to $15.2 \pm 2.7 \mathrm{pS}$ (Fig. 7C,D). This is consistent with the properties of the native olfactory cng channel from amphibians and mammals (Nakamura and Gold, 1987; Frings et al., 1992) and of the heteromeric rat olfactory cng channel expressed in transfected mammalian cells or in Xenopus oocytes (Bradley et al., 1994; Liman and Buck, 1994). The openings of the hippocampal cng channel are flickery, another characteristic of the heteromeric retinal (Chen et al., 1993) and olfactory (Bradley et al., 1994; Liman and Buck, 1994) channels. The homomeric rOCNC1 olfactory channel does not exhibit outward rectification or flickery opening behavior.

We also examined the effects of $\mathrm{Ni}^{2+}$ ions on cng channel activity in excised patches and compared these effects with the action of $\mathrm{Ni}^{2+}$ on the cloned heteromeric olfactory channel expressed in transfected cells. The $\mathrm{Ni}^{2+}$ response can provide a useful way to distinguish "retinal-like" and "olfactory-like" cng channels, because this ion dramatically increases the apparent affinity of the retinal rod channel for cAMP or cGMP but has little effect on the olfactory channel (Gordon and Zagotta, 1995a,b). We observed no potentiation by $\mathrm{Ni}^{2+}$ for either the cloned olfactory or hippocampal channels (data not shown). This result may not be informative for the rat, however, because the recently published sequence of the rat retinal rod channel, rRCNC1 (Barnstable and Wei, 1995), indicates that a histidine residue required for $\mathrm{Ni}^{2+}$ potentiation of the bovine rod channel (Gordon and Zagotta, 1995b) is not present in the the rat sequence.

In summary, our electrophysiological results indicate that the hippocampal cng channel is similar or identical to the heteromeric olfactory cng channel in all respects tested. This is consistent with the RNA and protein expression data (Figs. 1-5), which indicate that both olfactory subunits are expressed in hippocampal neurons, whereas the rRCNC1 retinal subunit is not expressed.

\section{$\mathrm{Ca}^{2+}$ influx into cultured hippocampal neurons in response to membrane-permeable cyclic nucleotide analogs}

The results described in the previous section indicate that $90 \%$ of cultured hippocampal neurons display whole-cell currents activated by cAMP or cGMP in the patch pipette. Because excised patches from the same cell population contained a channel with the electrophysiological characteristics of the heteromeric olfactory cng channel, it is likely that these whole-cell currents are attributable to the activity of the same channel. To obtain insights into whether this channel could be used to produce $\mathrm{Ca}^{2+}$. mediated changes in synaptic strength, we wished to determine whether we could use imaging techniques to detect $\mathrm{Ca}^{2+}$ influx into hippocampal neurons in response to elevation of cyclic nucleotides.

To do this, we first demonstrated that inward currents could be activated by perfusion of a membrane-permeable cGMP analog in most hippocampal neurons (13 of 16 cells tested). These currents 


\section{OCNC-1}
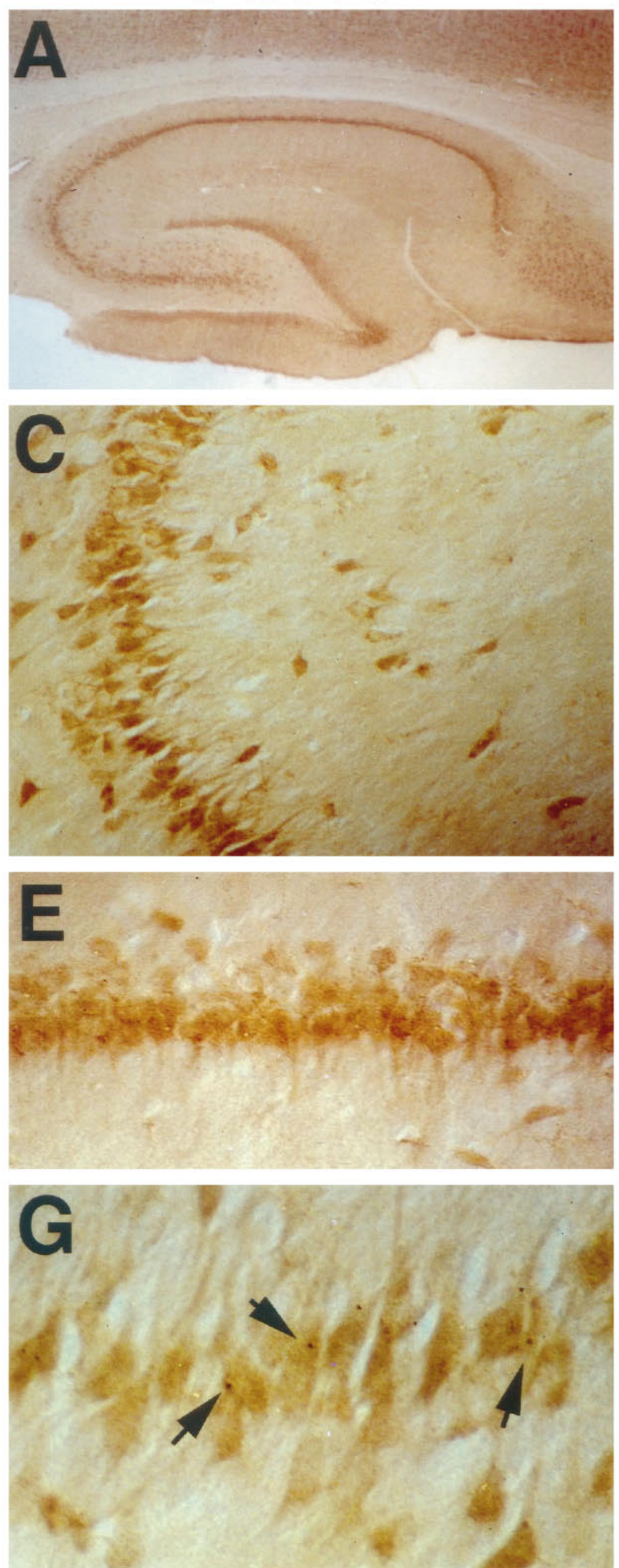

OCNC-2
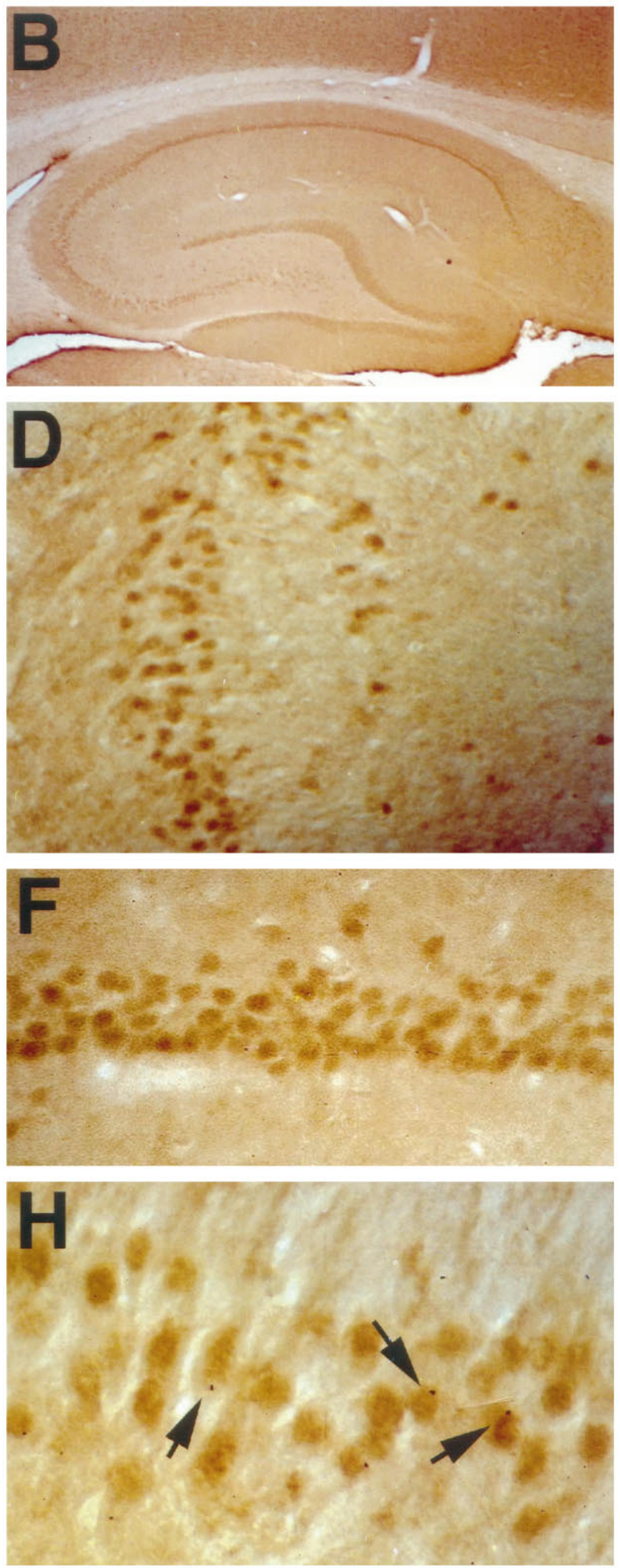

Figure 5. Immunolocalization of rOCNC1 and rOCNC2 in hippocampal sections. $A, C, E$, and $G$ show staining with affinity-purified antibody to rOCNC1; $B, D, F$, and $H$ show staining with anti-rOCNC2 mAb. Immunoreactivity to rOCNC1 and rOCNC2 is essentially colocalized; it is seen in hippocampal CA1 $(C, D)$ and CA3 $(E-H)$ regions, the subiculum, and the dentate gyrus. Staining for both is most prominent in cell bodies and proximal dendrites. Note the punctate staining in $G$ and $H$ (arrows). Photomicrographs were taken at $25 \times$ magnification $(A, B), 100 \times$ magnification $(C, D), 200 \times$ magnification $(E, F)$, and $400 \times$ magnification $(G, H)$. 

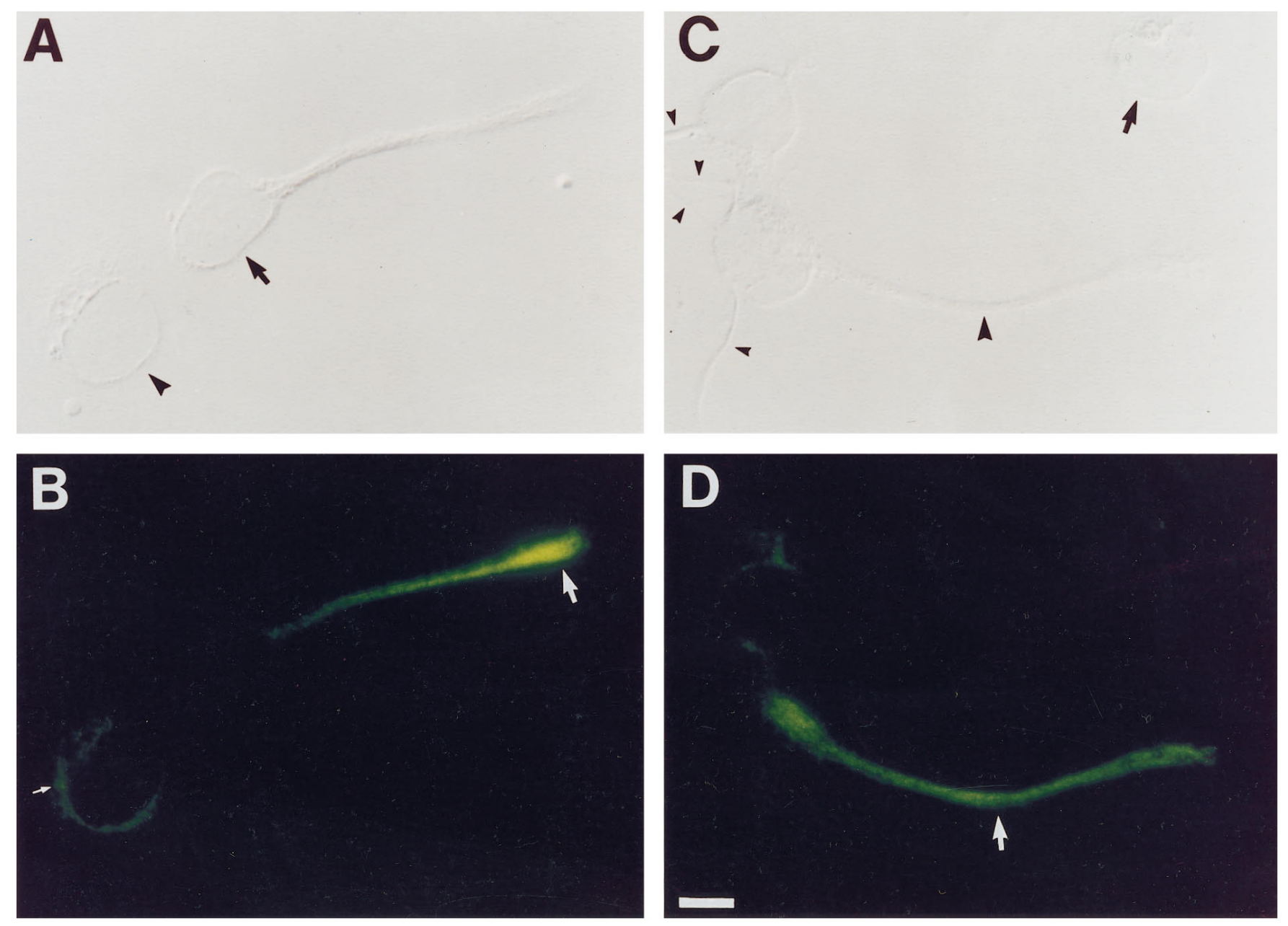

Figure 6. Expression of rOCNC2 on processes and growth cones of cultured embryonic hippocampal neurons. Two-day-old dissociated hippocampal cultures from E17 embryos were fixed with methanol and incubated with anti-rOCNC2 mAb followed by FITC-labeled secondary antibody. In $A$, $C$, cells are visualized using DIC optics; in $B, D, \mathrm{rOCNC} 2$ expression is visualized using fluorescence. One cell in $A$ (arrowhead) has not yet extended a process, and rOCNC2 is localized to internal membranes within this cell (small white arrow in $B$ ). The other cell (arrow in $A$ ) has extended a short process. rOCNC2 is no longer localized to the cell body but is present at high levels on the growth cone (white arrow in $B$ ) and at lower levels on the process. In $C$, two of the cells have extended short processes (small arrowheads), and one has a longer process (large arrowhead). rOCNC2 is selectively expressed on the longer process (white arrow in $D$ ). The arrow in $C$ indicates a cell that does not seem to express rOCNC2 at detectable levels. Scale bar, $7.2 \mu \mathrm{M}$.

were reversibly blocked by perfusion of $10 \mathrm{mM} \mathrm{Mg}^{2+}$ (Fig. $8 A$ ), consistent with the finding that cng channels are sensitive to divalent cation block (Root and MacKinnon, 1993; Zufall and Firestein, 1993; Eismann et al., 1994; Lynch and Lindermann, 1994). Similar results have been reported previously by others (Leinders-Zufall et al., 1995a).

To detect $\mathrm{Ca}^{2+}$ influx in response to cyclic nucleotide elevation, we then used a fura-2-based $\mathrm{Ca}^{2+}$ imaging system to analyze a population of hippocampal neurons. On perfusion of $1 \mathrm{~mm}$ 8-bromo cGMP, a three- to fourfold increase in fluorescence ratio $(340 \mathrm{~nm} / 363 \mathrm{~nm})$ was observed, indicating that the intracellular $\mathrm{Ca}^{2+}$ concentration had increased (Fig. $8 B$ ). This response was observed in $\sim 50 \%$ of neurons tested. The lower percentage of responding cells relative to the percentage observed in whole-cell recordings is probably attributable to the lower sensitivity of fura-2 imaging. The 8-bromo cGMP response was blocked by 10 $\mathrm{mM}$ extracellular $\mathrm{Mg}^{2+}$ and was not observed in the absence of extracellular $\mathrm{Ca}^{2+}$. It was smaller in magnitude and had a slower onset than the $\mathrm{Ca}^{2+}$ elevation produced in response to application of NMDA, which opens the $\mathrm{Ca}^{2+}$-permeable NMDA-type gluta- mate receptor channel (Fig. $8 B$ ). This probably reflects the time required for 8 -bromo cGMP to reach the interior of the neurons.

\section{Searching for expression of other cng channels in the hippocampus}

The channel observed in excised patches from hippocampal neurons is essentially identical in its behavior to the heteromeric olfactory channel. We wondered, however, whether previously unidentified cng channel subunits might also be expressed in the hippocampus. If so, differential expression of these subunits could produce distinct $\mathrm{Ca}^{2+}$ influx and current responses to cyclic nucleotide elevation in some neurons.

To investigate these issues, as well as to evaluate further whether the retinal rod channel subunits might be expressed in the hippocampus, we performed PCR experiments on first-strand cDNA from adult and embryonic hippocampus using degenerate primers derived from cyclic nucleotide binding domain sequences (Bradley et al., 1994). These primers amplify both olfactory and retinal channel sequences from cloned DNAs. Products of the expected size $(\sim 123 \mathrm{bp})$ generated from hippocampal cDNA were 
A
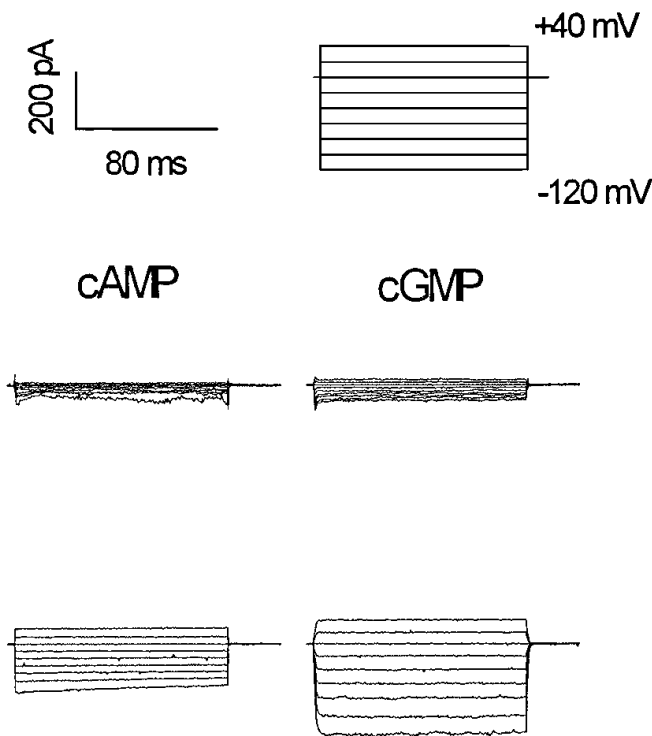

B

$2.5 \mathrm{~s}$
$2.4 \mathrm{pA}$
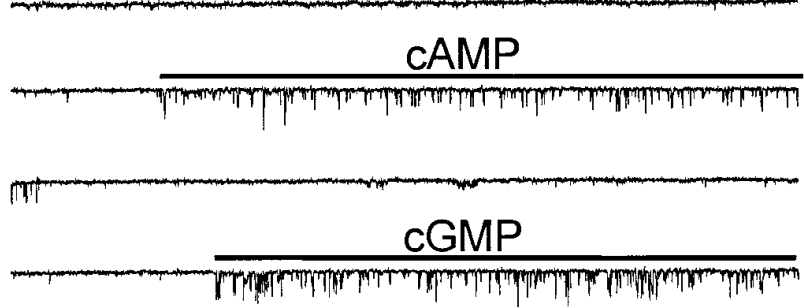

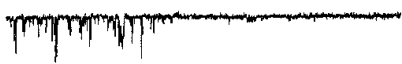

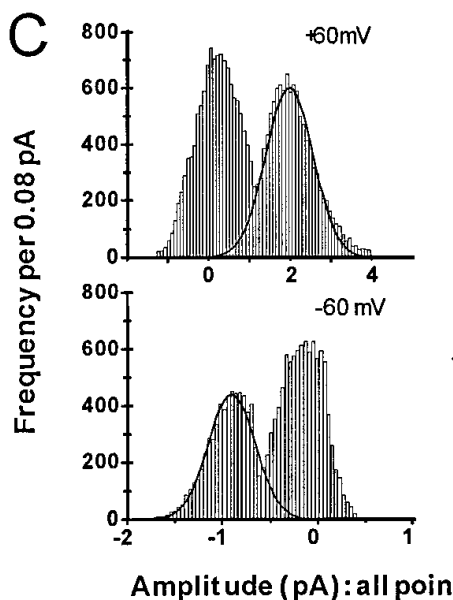

Amplit ude ( $p A)$ : all point

Figure 7. Whole-cell and excised inside-out patch recording of cng channels from cultured embryonic hippocampal neurons. $A$, Whole-cell recording. Currents activated in a cell by diffusion from patch pipettes backfilled with $100 \mu \mathrm{M}$ cAMP (left) or with $100 \mu \mathrm{M}$ cGMP in a different cell (right). The top traces show the voltage commands for each episode in a trial, with the time and current scales indicated at the left. The middle traces are currents recorded immediately after patch rupture, and the bottom traces are of currents recorded 4 min after patch rupture. $B$, Inside-out patch recording. Continuous recordings from an inside-out patch excised from a cell body of a hippocampal neuron are shown. The patch was held at $-60 \mathrm{mV}$. Cyclic nucleotides were perfused onto the cytoplasmic side of the patch for $10 \mathrm{sec}$ intervals, at the times indicated by the horizontal bars. The pipette and perfusion solutions were symmetrical and free of divalent cations. $C, D$, Amplitude histograms and current-voltage relations $(I-V)$. The amplitude histograms were constructed from a patch perfused with $10 \mu \mathrm{M}$ cAMP. The $I-V$ relation was plotted for the same patch.

cloned and sequenced. This analysis identified the rOCNC1 and rONCN2 sequences, but we did not recover any clones corresponding to rRCNC1 or rRCNC2; however, we did amplify a sequence (GenBank U76221) that is similar to that of a cng channel expressed in bovine cone photoreceptors and sperm (Weyand et al., 1994). There were 14 nucleotide (of 90 total nonprimer bases) and two amino acid changes between the rat hippocampal sequence and the bovine sequence. If our new sequence represents the rat homolog of the bovine cone channel, this would be of interest because the cone channel is highly permeable to $\mathrm{Ca}^{2+}$ (1.5-fold greater permeability than the rOCNC1 homomeric channel), but unlike the olfactory channel it cannot be blocked completely by $10 \mathrm{~mm}$ extracellular $\mathrm{Mg}^{2+}$.

\section{DISCUSSION}

In this paper, the expression of the "olfactory" cng channel subunits rOCNC1 and rOCNC2 in mammalian brain is demonstrated by RT-PCR, in situ hybridization, and immunohistochemistry with subunit-specific antibodies. These channel subunits are widely expressed in the hippocampus, olfactory bulb, cerebellum, and cortex (Fig. 4 and data not shown). We characterized hip- pocampal expression in detail and showed that the channel subunits are localized to cell bodies and processes of CA1 and CA3 pyramidal neurons, as well as on granule neurons in the dentate gyrus (Fig. 5). We did not detect expression of retinal rod photoreceptor cng channel mRNA or protein in any part of the brain.

Having shown that the olfactory channel subunits are expressed in the adult hippocampus, we then investigated the localization and function of the channel in dissociated hippocampal cultures from E17 embryos. The rOCNC2 subunit is expressed on neuronal processes in these cultures (Fig. 6). Recordings made from inside-out patches from the cultured hippocampal neurons showed expression of a cyclic nucleotide-gated conductance with high sensitivity $(<10 \mu \mathrm{M})$ to cAMP. Together, these data indicate that hippocampal neurons express a cng channel that is similar or identical to the heteromeric olfactory cng channel.

\section{Involvement of cyclic nucleotides in synaptic plasticity}

In the mammalian hippocampus, LTP is studied as a model of use-dependent synaptic strengthening that is assumed to be a physiological mechanism for information storage. NMDA receptor-dependent LTP in the Schaffer collateral pathway in- 


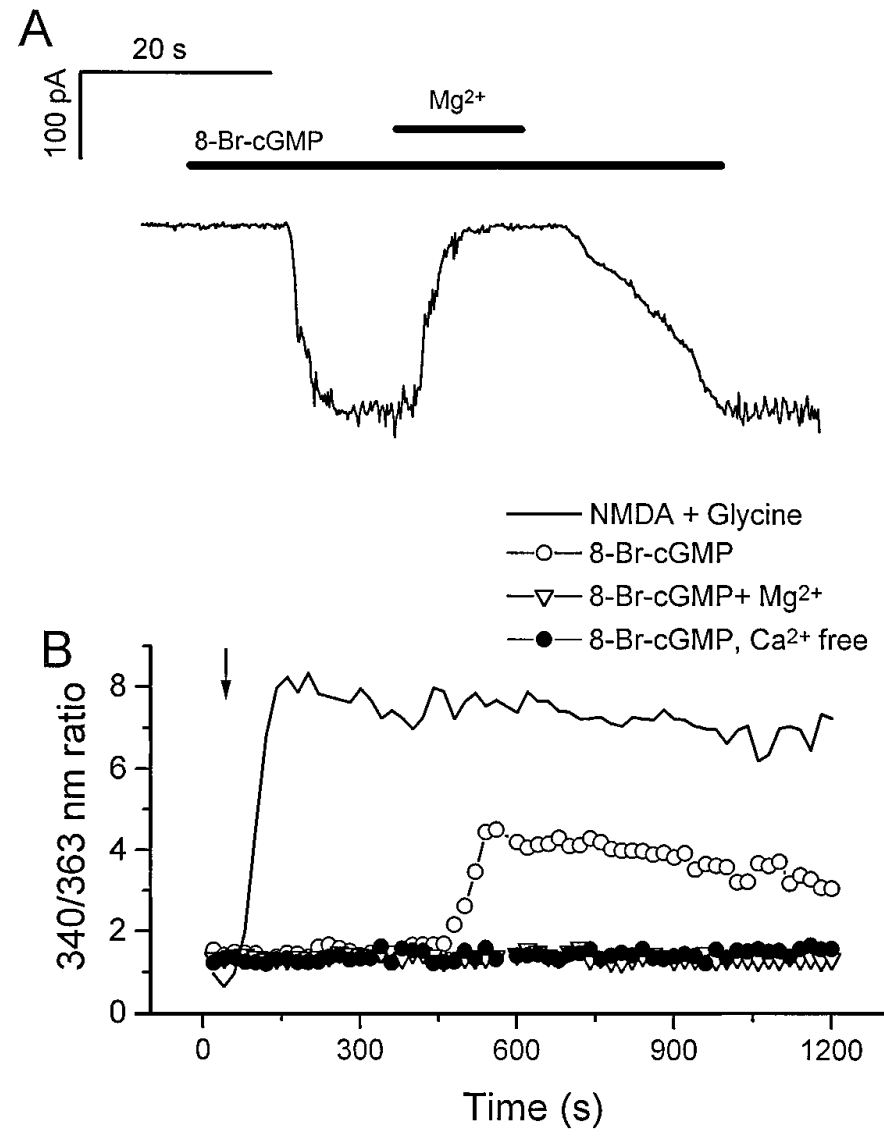

Figure 8. Effect of membrane-permeable cyclic nucleotide on cultured hippocampal neurons. $A$, Effects of 8-bromo-cGMP on a hippocampal neuron from a 7-d-old culture. The recording was performed in a wholecell patch-clamp configuration. The recording chamber was perfused constantly with bath solution. The holding potential was $-80 \mathrm{mV}$. 8-bromo-cGMP was diluted in the bath solution or in a bath solution containing $10 \mathrm{mM} \mathrm{MgCl}$ in a final concentration of $1 \mathrm{~mm}$. Duration of drug delivery is indicated by the horizontal bars. $B$, Fura-2 calcium measurement of cultured hippocampal neurons. Measurements were made from separate coverslips of the same neuronal culture. The measurements were the averages of responses of multiple cells (8-bromo-cGMP, 6 cells; NMDA, 16 cells; 8-bromo-cGMP with extracellular $\mathrm{Mg}^{2+}$, 13 cells; 8-bromo-cGMP without extracellular $\mathrm{Ca}^{2+}, 11$ cells). The arrow indicates the starting point for drug application. The long delay before the onset of the drug response in this system is attributable to the slow diffusion of 8-bromo-cGMP into the space between the immersion objective and the slide (an upright microscope was used in these experiments). Drugs were present at all times, and no perfusion was used during the measurements. The final concentrations of the drugs were NMDA, $100 \mu \mathrm{M}$; glycine, 10 $\mu \mathrm{M}$; 8-bromo-cGMP, $1 \mathrm{~mm}$; and $\mathrm{Mg}^{2+}, 10 \mathrm{~mm}$.

volves the axons of the CA3 pyramidal cells, which synapse on dendrites of the pyramidal cells in the CA1 region. LTP can be triggered in CA1 neurons by activation of postsynaptic NMDAtype glutamate receptor channels. This occurs when glutamate is released from presynaptic terminals coincident with postsynaptic depolarization. Depolarization of the postsynaptic cell is required to relieve an extracellular voltage-dependent block by $\mathrm{Mg}^{2+}$ of the NMDA receptor channel. The NMDA channel is permeable to $\mathrm{Ca}^{2+}$, and elevated intracellular $\mathrm{Ca}^{2+}$ seems to act as a trigger for LTP.

Postsynaptic $\mathrm{Ca}^{2+}$ has many effects in CA1 pyramidal cells. One of these is to directly or indirectly activate $\mathrm{Ca}^{2+} /$ calmodulin (CaM)-sensitive adenylyl cyclases (ACs). The cAMP thus gener- ated is expected to activate PKA. A PKA inhibitor, Rp-cAMPS, and a PKA activator, Sp-cAMPS, respectively suppress and enhance L-LTP, which also requires the induction of new transcription (Frey et al., 1993). It was thus concluded that PKA is necessary for L-LTP; however, Rp-cAMPS is also an antagonist of the olfactory cng channel, and Sp-cAMPS is an agonist (Kramer and Tibbs, 1996). It is possible, therefore, that $\mathrm{Ca}^{2+}$ flow through the cng channel could also be an important effector for cAMP during maintenance of LTP in CA1 neurons. The cng channel is also suited for such a role because of its lack of desensitization, which provides for a continuous ion flux as long as cyclic nucleotides are present.

LTP in the mossy fiber pathway, in which axons of dentate granule cells synapse on dendrites of CA3 neurons, is NMDA receptor-independent and does not require elevation of postsynaptic $\mathrm{Ca}^{2+}$. The early phase of mossy fiber LTP seems to be primarily a presynaptic phenomenon mediated by an increased probability of transmitter release. AC activators such as forskolin or membrane-permeable cAMP analogs cause presynaptic enhancement of mossy fiber responses and occlude mossy fiber LTP. These data suggest that cAMP elevation and mossy fiber LTP interact with one another and that they share a common process that is expressed presynaptically.

It has been proposed that induction of the early phase of mossy fiber LTP involves activation of type $1 \mathrm{AC}$ by $\mathrm{Ca}^{2+} / \mathrm{CaM}$ produced after influx of presynaptic $\mathrm{Ca}^{2+}$ produced as a consequence of tetanic stimulation (Weisskopf et al., 1994). A later phase of mossy fiber LTP produced by repeated tetanization also requires cAMP elevation (Huang et al., 1994). Induction of both the early and late phases of mossy fiber LTP can be facilitated by stimulation of $\beta$-adrenergic receptors, which activate $A C$ via $\mathrm{G}_{\mathrm{s}}$ (Huang and Kandel, 1996). Finally, cAMP elevation is required for the induction of a form of presynaptic LTP at cerebellar parallel fiber synapses (Salin et al., 1996). As discussed above for CA1 L-LTP, the evidence for PKA as the exclusive effector for cAMP in mossy fiber and parallel fiber LTP is based largely on studies with inhibitors and activators, including Rp-cAMPS, Rp-8-CPTcAMPS, and Sp-cAMPS, and some of these drugs are also olfactory cng channel antagonists and agonists. Thus, the current results do not exclude a potential role for presynaptically expressed cng channels in facilitating entry of $\mathrm{Ca}^{2+}$ into terminals.

cGMP elevation is essential for LTD in cerebellar Purkinje neurons. NO is produced as a consequence of simultaneous stimulation of climbing fiber and parallel fiber inputs to the Purkinje cells, and it activates soluble GC in the Purkinje cell. Inhibitor studies have suggested that the effector for cGMP in the induction of LTD is PKG. The olfactory cng channel, which is opened by low concentrations of cGMP and is expressed in Purkinje cells, could also be an effector for GC (Fig. 9). A possible precedent for this mechanism is provided by a cGMP-sensitive current in retinal ganglion cells that is activated by NO (Ahmad et al., 1994). Broillet and Firestein (1996) have also found that the olfactory cng channel can be directly gated by NO.

\section{Potential physiological roles of "olfactory" cng channels in brain neurons}

The heteromeric olfactory cng channel is analogous in certain respects to the NMDA receptor channel: it is permeable to $\mathrm{Ca}^{2+}$, activated by ligand binding in a cooperative fashion, and blocked by extracellular $\mathrm{Mg}^{2+}$ in a voltage-dependent manner. The voltage dependence of the $\mathrm{Mg}^{2+}$ block, however, is rather weak for the cng channel compared with the NMDA receptor channel. 

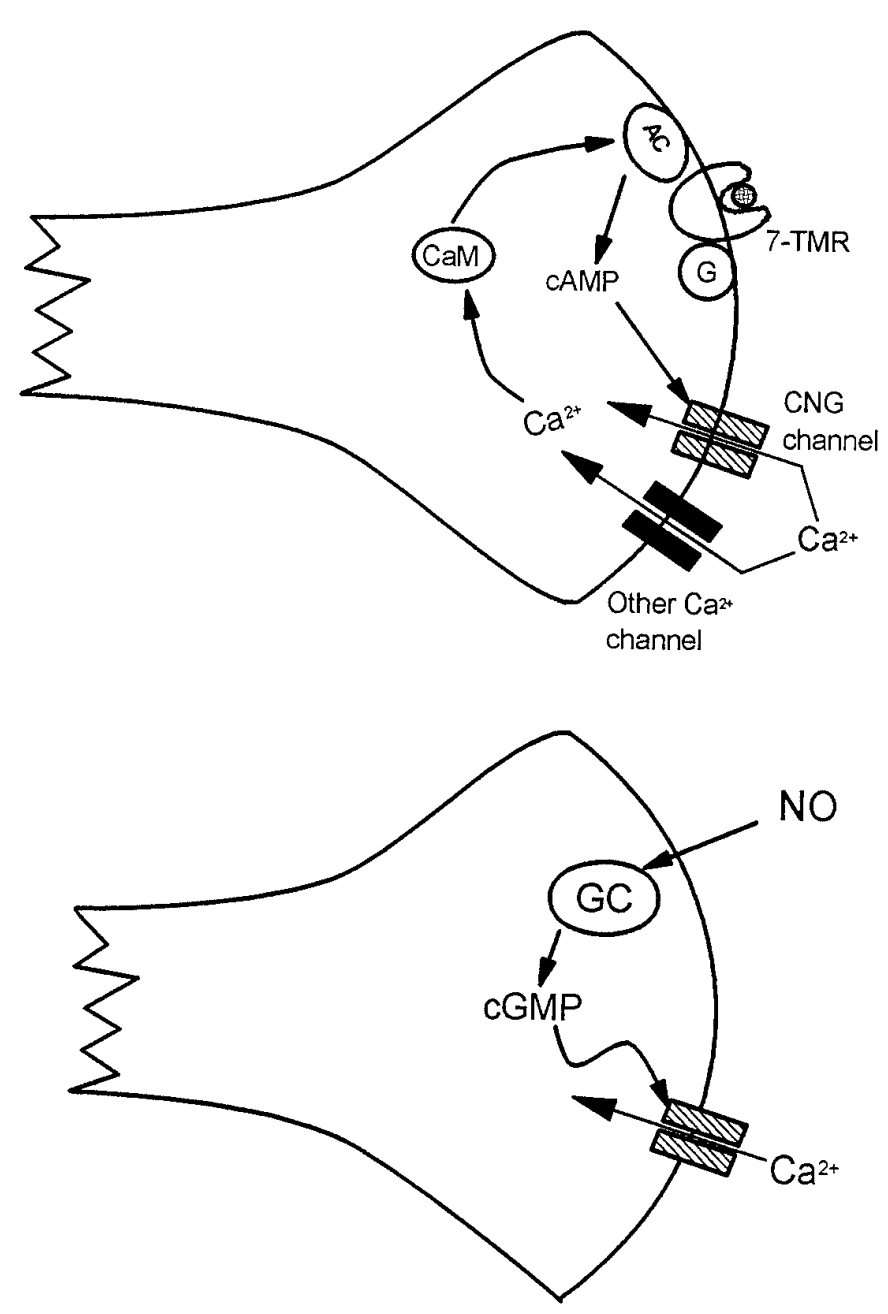

Figure 9. Potential functions of "olfactory" cng channels in nerve terminals in the brain. On the left, a hypothetical positive feedback loop is depicted in which agonist (hatched circle) binding to a 7-helix receptor (7-TMR) coupled to AC activation via a G-protein causes production of cAMP, opening the cng channel and admitting $\mathrm{Ca}^{2+}$. This $\mathrm{Ca}^{2+}$, together with $\mathrm{Ca}^{2+}$ entering through other channels, binds to $\mathrm{CaM}$, which further stimulates AC activity. Note also that this loop might be "self-damping," because $\mathrm{Ca}^{2+} / \mathrm{CaM}$ binds to the olfactory channel and reduces its affinity for cAMP (for review, see Finn et al., 1996). On the right, $N O$ activates $G C$, producing cGMP, which causes opening of the cng channel and an influx of $\mathrm{Ca}^{2+}$.

The NMDA receptor channel is uniquely suited to its role in the establishment of LTP in CA1 neurons, because it admits $\mathrm{Ca}^{2+}$ in response to the coincident inputs of glutamate and postsynaptic depolarization. This $\mathrm{Ca}^{2+}$ then triggers the events leading to synaptic strengthening. The cng channel, on the other hand, may be suited for a role in the maintenance of LTP, because it will remain open as long as cAMP levels are elevated. The proposed role of cAMP in LTP in CA1 neurons is in its maintenance and conversion into L-LTP. This is believed to be mediated through persistent activation of PKA but could also involve sustained $\mathrm{Ca}^{2+}$ influx through the cng channel. This $\mathrm{Ca}^{2+}$ influx would activate the $\mathrm{Ca}^{2+} / \mathrm{CaM}$-sensitive $\mathrm{AC}$, producing a feedback loop that would maintain high cAMP levels and a continuous $\mathrm{Ca}^{2+}$ influx (Fig. 9).

To understand how the cng channel functions in brain neurons, it is important to determine its precise localization. Our data indicate that the channel subunit proteins are located on processes of hippocampal neurons and are likely to be concentrated at synaptic terminals (Fig. 6 and data not shown), but we do not know whether these terminals are presynaptic, postsynaptic, or both.

Interestingly, the second subunit, $\mathrm{rOCNC} 2$, is localized to a subset of growth cones and processes in cultured embryonic hippocampal neurons and is largely absent from cell bodies. In the adult hippocampus, however, we observe dark cell-body staining with the mAb against this subunit. These data could indicate that the heteromeric channel also has some developmental role in hippocampal neurons. In this regard, it is intriguing that the expression of rOCNC2 is dramatically upregulated in regenerating olfactory neurons after transection of the olfactory nerve (L. Stern and G. V. Ronnett, unpublished observations). These regenerating neurons are extending axons to reinnervate the olfactory bulb. Finally, the tax- 2 and $\operatorname{tax}-4$ genes in the nematode Caenorhabditis elegans, which are essential for formation of the appropriate synaptic connections between chemosensory neurons and the nerve ring, encode proteins that are closely related to the $\alpha$ and $\beta$ subunits of cng channels, respectively (Coburn and Bargmann, 1996; Komatsu et al., 1996). These data suggest that cng channels could have roles in determining patterns of synaptic connections in both vertebrates and invertebrates.

\section{REFERENCES}

Ahmad I, Leinders-Zufall T, Kocsis JD, Shepherd GM, Zufall F, Barnstable CJ (1994) Retinal ganglion cells express a cGMP-gated cation conductance activatable by nitric oxide donors. Neuron 12:155-165.

Barnstable CJ, Wei JY (1995) Isolation and characterization of the alpha-subunit of rod photoreceptor cGMP-gated cation channel. J Mol Neurobiol 6:289-302.

Bradley J, Li J, Davidson N, Lester HA, Zinn K (1994) Heteromeric olfactory cyclic nucleotide-gated channels: a subunit that confers increased sensitivity to cAMP. Proc Natl Acad Sci USA 91:8890-8894.

Broillet MC, Firestein S (1996) Direct activation of the cyclic nucleotidegated channel through modification of sulfhydryl-groups by NO compounds. Neuron 16:377-385.

Buck L, Axel R (1991) A novel multigene family may encode odorant receptors: a molecular basis for odor recognition. Cell 65:175-187.

Chen T-Y, Peng Y-W, Dhallan RS, Ahamed B, Reed RR, Yau K-W (1993) A new subunit of the cyclic nucleotide-gated cation channel in retinal rods. Nature 362:764-767.

Coburn C, Bargmann CI (1996) A putative cyclic nucleotide-gated channel is required for sensory development and function in C. elegans. Neuron 17:695-706.

Eismann E, Muller F, Heinemann SH, Kaupp UB (1994) A single negative charge within the pore region of a cGMP-gated channel controls rectification, $\mathrm{Ca}^{2+}$ blockage, and ionic selectivity. Proc Natl Acad Sci USA 91:1109-1113.

Elhusseini AED, Bladen C, Vincent SR (1995) Expression of the olfactory cyclic-nucleotide gated channel (cng1) in the rat-brain. NeuroReport 6:1459-1463.

Finn JT, Grunwald ME, Yau KW (1996) Cyclic nucleotide-gated ion channels: an extended family with diverse functions. Annu Rev Physiol 58:395-426.

Frey U, Huang YY, Kandel ER (1993) Effects of cAMP simulate a late stage of LTP in hippocampal CA1 neurons. Science 260:1661-1664.

Frings S, Lynch JW, Lindemann B (1992) Properties of cyclic nucleotidegated channels mediating olfactory transduction: activation, selectivity, and blockage. J Gen Physiol 100:45-67.

Frings S, Seifert R, Godde M, Kaupp UP (1995) Profoundly different calcium permeation and blockage determine the specific function of distinct cyclic nucleotide-gated channels. Neuron 15:169-179.

Frohman MA (1994) On beyond classic RACE (Rapid Amplification of cDNA Ends). PCR Methods Appl 4:40-58.

Gordon SE, Zagotta WN (1995a) Subunit interactions in coordination of $\mathrm{Ni}^{2+}$ in cyclic nucleotide-gated. Proc Natl Acad Sci USA 92:10222-10226. 
Gordon SE, Zagotta WN (1995b) A histidine residue associated with the gate of the cyclic nucleotide-activated channels in rod photoreceptors. Neuron 14:177-183.

Huang YY, Kandel ER (1996) Modulation of both the early and the late-phase of mossy fiber LTP by the activation of beta-adrenergic receptors. Neuron 16:611-617.

Huang YY, Li XC, Kandel ER (1994) cAMP contributes to mossy fiber LTP by initiating both a covalently mediated early phase and macromolecular synthesis-dependent late-phase. Cell 79:69-79.

Ingi T, Ronnett GV (1995) Direct demonstration of a physiological role for carbon monoxide in olfactory receptor neurons. J Neurosci $15: 8214-8222$.

Kingston PA, Zufall F, Barnstable CJ (1996) Rat hippocampal neurons express genes for both rod retinal and olfactory cyclic nucleotide-gated channels: novel targets for cAMP/cGMP function. Proc Natl Acad Sci USA 93:10440-10445.

Komatsu H, Mori J, Rhee JS, Akaike N, Ohshima Y (1996) Mutations in a cyclic nucleotide-gated channel lead to abnormal thermosensation and chemosensation in C. elegans. Neuron 17:707-718.

Korschen HG, Illing M, Seifert R, Sesti F, Williams A, Gotzes S, Colville C, Muller F, Dose A, Godde M, Modday L, Molday RS (1995) A 240 $\mathrm{kDa}$ protein represents the complete beta-subunit of the cyclic nucleotide-gated channel from rod photoreceptors. Neuron 15:627-636.

Kramer RH, Tibbs GR (1996) Antagonists of cyclic nucleotide-gated channels and molecular mapping of their site of action. J Neurosci 16:1285-1293.

Leinders-Zufall T, Rosenboom H, Barnstable CJ, Shepherd GM, Zufall F (1995a) A calcium-permeable cGMP-activated cation conductance in hippocampal neurons. NeuroReport 6:1761-1765.

Leinders-Zufall T, Shepherd GM, Zufall F (1995b) Regulation of cyclic nucleotide-gated channels and membrane excitability in olfactory receptor cells by carbon monoxide. J Neurophysiol 74:1498-1508.

Liman ER, Buck LB (1994) A second subunit of the olfactory cyclic nucleotide-gated channel confers high sensitivity to cAMP. Neuron 13:611-621.

Linden DJ (1994) Long-term synaptic depression in the mammalian brain. Neuron 12:457-472.

Lowe G, Gold G (1993) Nonlinear amplification by calcium-dependent chloride channels in olfactory receptor cells. Nature 366:283-286.

Lynch JW, Lindermann B (1994) Cyclic nucleotide-gated channels of rat olfactory receptor cells: divalent cations control the sensitivity to cAMP. J Gen Physiol 103:87-106.

Molday RS, Molday LL, Dosé A, Clark-Lewis I, Illing M, Cook NJ, Eismann E, Kaupp UB (1991) The cGMP-gated channel of the rod photoreceptor cell characterization and orientation of the amino terminus. J Biol Chem 266:21917-21922.

Nakamura T, Gold GH (1987) A cyclic nucleotide-gated conductance in olfactory receptor cilia. Nature 325:342-344.

Nawy S, Jahr CE (1991) cGMP-gated conductance in olfactory receptor cilia. Nature 325:342-344.

Root MJ, MacKinnon R (1993) Identification of an external divalent cation-binding site in the pore of a cGMP-activated channel. Neuron 11:459-466.

Roskams AJ, Bredt DS, Dawson TM, Ronnett GV (1994) Nitric-oxide mediates the formation of synaptic connections in developing and regenerating olfactory receptor neurons. Neuron 13:289-299.

Salin PA, Malenka RC, Nicoll RA (1996) Cyclic-AMP mediates a presynaptic form of LTP at cerebellar parallel fiber synapses. Neuron 16:797-803.

Schaeren-Wiemers N, Gerfin-Moser A (1993) A single protocol to detect transcripts of various types and expression levels in neural tissues and cultured cells: in situ hybridization using digoxigenin-labeled cRNA probes. Histochemistry 100:431-440.

Schuman EM, Madison DV (1994) Nitric-oxide and synaptic function. Annu Rev Neurosci 17:153-183.

Stein R, Mori N, Matthews K, Lo L-C, Anderson DJ (1988) The NGFinducible SCG10 mRNA encodes a novel membrane-bound protein present in growth cones and abundant in developing neurons. Neuron 1:463-476.

Weisskopf MG, Castillo PE, Zalutsky RA, Nicoll RA (1994) Mediation of hippocampal mossy fiber long-term potentiation by cyclic-AMP. Science 265:1879-1882.

Weyand I, Godde M, Frings S, Weiner J, Muller F, Alenhofen W, Hatt H, Kaupp UB (1994) Cloning and functional expression of a cyclic nucleotide-gated channel from mammalian sperm. Nature 368:859-863.

Zagotta WN, Siegelbaum SA (1996) Structure and function of cyclic nucleotide-gated channels. Annu Rev Neurosci 19:235-263.

Zufall F, Firestein S (1993) Divalent-cations block the cyclic nucleotide-gated channel of olfactory receptor neurons. J Neurophysiol 69:1758-1768. 